\title{
Environmental Factors Influencing Germination in Seeded Seashore Paspalum
}

\author{
J.S. Shin \\ Seminis Korea, Gwanghui B/D, 13F, Gwanghui-Dong, Jung-Gu, Seoul, 100- \\ 710, Korea
}

\section{P. Raymer}

Department of Crop and Soil Sciences, University of Georgia, Griffin Campus, Griffin, GA 30223

\section{W. Kim ${ }^{1}$}

Division of Biotechnology, College of Life Sciences and Biotechnology, Korea University, Anam-Dong, Seongbuk-Gu, Seoul, 136-701, Korea

Additional index words. seashore paspalum, germination, seeded cultivar

\begin{abstract}
Seashore paspalum (Paspalum vaginatum O. Swartz) is a perennial warmseason grass that is rapidly gaining popularity for use on golf courses and athletic fields. The first seeded cultivar of seashore paspalum was recently developed. Seed from the pilot production of this cultivar harvested in Oregon during 2002 by Turf-Seeds, Inc. demonstrated a high level of apparent seed dormancy with a tetrazolium test of $91 \%$ but a germination rate of less than $5 \%$ at room temperature. This seed was used in laboratory experiments to determine the effect of a number of environmental factors on germination response in this new turf species. Treatment factors are germination media, constant and alternating (night/day) temperatures, and light. A strong and significant effect of temperature on germination was observed. Total germination was increased at higher temperatures. At the same daytime temperature, seed germination under alternating temperature was better than germination at constant temperature. The effect of light on germination was significant at $20,25,30,20 / 35{ }^{\circ} \mathrm{C}$ in water and at $25 / 35{ }^{\circ} \mathrm{C}$ in $0.2 \%$ $\mathrm{KNO}_{3}$ germination media. However, the effect of light on germination in $\mathrm{KNO}_{3}$ media was not significant at $35{ }^{\circ} \mathrm{C}$ constant and $20 / 30{ }^{\circ} \mathrm{C}$ alternating temperatures. Alternating temperature used in conjunction with $\mathrm{KNO}_{3}$ media reduced the requirement for light. The use of $0.2 \% \mathrm{KNO}_{3}$ rather than water as the germination media increased germination in most temperature and light treatments. Based on our results, maximum germination percentage was obtained when seed was germinated at $35{ }^{\circ} \mathrm{C}$ constant or $20 / 35{ }^{\circ} \mathrm{C}$ alternating temperature. However, when we consider field application, $25 / 35^{\circ} \mathrm{C}$ with light is more realistic condition in field. Therefore, recommended seed germination test condition is at $25 / 35{ }^{\circ} \mathrm{C}$ with $\mathrm{KNO}_{3}$ treatment.
\end{abstract}

Seashore paspalum (Paspalum vaginatum O. Swartz, $2 \mathrm{n}=2 \mathrm{x}=20$ ) is a self-incompatible warm-season perennial grass (Carpenter, 1958). Seashore paspalum can tolerate irrigation with saline water (Carrow and Duncan, 1998), waterlogging (Colman and Wilson, 1960), severe soil pH (range, 3.610.2; Duncan, 1994), drought (Huang et al., 1997), and low light intensity or shade conditions (Jiang et al., 2004). As a result of its aggressive and fast-growing characteristics under extremely warm and humid climates, it plays an important role in preventing soil erosion in coastal environments and has been used for the bioremediation of contaminated or unproductive soils. More recently, im-

\footnotetext{
Received for publication 6 Mar. 2006. Accepted for publication 5 Apr. 2006. This work was supported by Ministry of Education and Human Resources Development in Korea, 2005.

${ }^{1}$ To whom correspondence should be addressed;
} e-mailkwook@korea.ac.kr. determine the environmental factors such as temperature and light on seed germination; and 2) to develop a seed germination testing protocol that accurately reflects the germination potential of unknown seed lots of seashore paspalum.

\section{Materials and Methods}

Seeds of 'SeaSpray' seashore paspalum used in this study were produced in a pilot production field by Turf-Seed, Inc. of Hubbard, Ore., during 2002. Tetrazolium tests conducted at Turf-Seed germination laboratory indicated $91 \%$ viable seed. Seed samples used in this study were received at our laboratory in December 2002 and maintained in storage at $4{ }^{\circ} \mathrm{C}$ before use in these experiments. Three different germination factors (germination media, temperature, and light) were tested in a $2 \times 7 \times 2$ factorial treatment design with 3 replications. Solutions of $0.2 \%$ (w/v) $\mathrm{KNO}_{3}$ and $\mathrm{H}_{2} \mathrm{O}$ were tested as germination media. The seven temperature treatments tested were constant temperature at 20, 25,30 , and $35^{\circ} \mathrm{C}$ and alternating night/day temperature at $20 / 30,25 / 35$, and $20 / 35{ }^{\circ} \mathrm{C}$. Light treatments were constant darkness (dark) and alternation (dark/light for 16/8 hours).

All germination tests were conducted in transparent $11 \times 11 \times 3.5-\mathrm{cm}$ polystyrene germination boxes with friction-fitting lids (Hoffman Manufacturing, Inc., Albany, Ore.) and with two layers of steel blue blotter germination paper (Anchor Paper, St. Paul, Minn.). Each experimental unit consisted of 100 seeds placed on germination paper soaked in $17 \mathrm{~mL}$ of germination media and placed in a Conviron Model E15 growth chamber (Controlled Environments Limited, Winnipeg, Man.). The germination boxes were rearranged daily to minimize the effects of potential temperature differences within the chambers. The number of germinated seeds, defined as those with both plumule and radicle protruding through the testa, was recorded daily for $21 \mathrm{~d}$. Data were statistically analyzed (SAS Institute). When the analysis of variance was significant, means were compared by least significant differences (LSD).

\section{Results and Discussion} mercialized by Turf-Seed, Inc. of Hubbard, Ore. Although seeded paspalum has great potential for several commercial applications, concerns regarding low germination rate and poor uniformity of germination time have arisen. Research is needed to improve total germination and uniformity of germination; otherwise, these issues could hinder marketability and commercial success of this and future seeded paspalum cultivars.

Characterization of the environmental factors that influence germination of seeded paspalum could also provide useful information for the development of recommended cultural protocols for establishing grass field. The objectives of this study were 1) to 
Table 1. The effect of environmental factors (light, temperature, and $\mathrm{KNO}_{3}$ ) on the mean germination percentage of seeded seashore paspalum after 3 weeks.

\begin{tabular}{|c|c|c|c|c|c|c|}
\hline \multirow[b]{2}{*}{ Temperature } & \multicolumn{3}{|c|}{$8 \mathrm{~h}$ light } & \multicolumn{3}{|c|}{ Constant darkness } \\
\hline & $\mathrm{H}_{2} \mathrm{O}$ & $0.2 \% \mathrm{KNO}_{3}$ & $\mathrm{H}_{2} \mathrm{O}$ vs. $0.2 \% \mathrm{KNO}_{3}$ & $\mathrm{H}_{2} \mathrm{O}$ & $0.2 \% \mathrm{KNO}_{3}$ & $\mathrm{H}_{2} \mathrm{O}$ vs. $0.2 \% \mathrm{KNO}_{3}$ \\
\hline $25^{\circ} \mathrm{C}$ & $4.7 \mathrm{~b}$ & $29.7 \mathrm{c}$ & $\mathrm{y}$ & $0.3 \mathrm{c}$ & $0.0 \mathrm{e}$ & - \\
\hline $30^{\circ} \mathrm{C}$ & $12.7 \mathrm{~b}$ & $57.7 \mathrm{~b}$ & $\mathrm{y}$ & $0.7 \mathrm{c}$ & $6.0 \mathrm{~d}$ & $\mathrm{z}$ \\
\hline $20 / 30{ }^{\circ} \mathrm{C}$ & $8.0 \mathrm{~b}$ & $55.3 \mathrm{~b}$ & $\mathrm{y}$ & $2.7 \mathrm{c}$ & $50.3 \mathrm{c}$ & $\mathrm{y}$ \\
\hline $20 / 35^{\circ} \mathrm{C}$ & $53.0 \mathrm{a}$ & $70.0 \mathrm{a}$ & $\mathrm{y}$ & $34.7 \mathrm{a}$ & $77.3 \mathrm{a}$ & y \\
\hline $25 / 35^{\circ} \mathrm{C}$ & $53.0 \mathrm{a}$ & $77.0 \mathrm{a}$ & $\mathrm{y}$ & $20.7 \mathrm{~b}$ & $68.7 \mathrm{~b}$ & $\mathrm{y}$ \\
\hline
\end{tabular}

${ }^{\mathrm{z}, \mathrm{S}}$ Significant at $P=0.05$ and 0.01 , respectively.

Values followed by the same letter within a column are not significantly different $(\mathrm{LSD}, P<0.05)$.

The best germination rate was obtained with $\mathrm{KNO}_{3}$ treatment at a constant temperature of $35{ }^{\circ} \mathrm{C}$ or at alternating temperatures of $20 / 35$ and $25 / 35{ }^{\circ} \mathrm{C}$ regardless of presence of light. This finding indicates that $\mathrm{KNO}_{3}$ in combination with higher temperature can substitute for the light. Germination rate of seeded seashore paspalum was significantly affected by temperature (Table 1). Under the constant temperature regimes, higher temperatures induced better germination rates. Final germination percentages at $20 / 35$ and $25 / 35^{\circ} \mathrm{C}$ were higher than germination percentages at $20 / 30{ }^{\circ} \mathrm{C}$ in altering temperature regimes. Germination rate at $20 / 30{ }^{\circ} \mathrm{C}$ was lower than germination at $20 / 35{ }^{\circ} \mathrm{C}$. It indicated that germination of seeded seashore paspalum was more influenced by daytime temperature than by night temperature. Alternating temperature used in conjunction with $\mathrm{KNO}_{3}$ reduced the requirement for light.

When seashore paspalum seeds were tested under varying germination temperatures, greatly different germination responses were observed (Fig. 1). Light, higher temperature, and $\mathrm{KNO}_{3}$ all improved germination speed as well as final germination rate. Germination was initiated earlier at 20/35 ${ }^{\circ} \mathrm{C}$ when seeds were placed in $\mathrm{KNO}_{3}$ media rather than in water. Light (alternating) also improved the rate of germination, especially when $\mathrm{KNO}_{3}$ was used at lower germination temperatures. The highest germination rate at week 1 was $40 \%$ observed at $20 / 35^{\circ} \mathrm{C}$ with light and $\mathrm{KNO}_{3}$ (Fig. 1). At 2 and 3 weeks, no significant differences in germination rate were observed among the $35,20 / 35$, and $25 / 35^{\circ} \mathrm{C}$ temperature treatments with light. The uniformity of germination was the highest at $20 / 35^{\circ} \mathrm{C}$ than at 35 and $25 / 35^{\circ} \mathrm{C}$.

The successful establishment of turf from seashore paspalum seed is greatly dependent on the germination response to the environment. Seed germination usually occurs in the growing season after seed dormancy was being removed. Increasing temperatures, alternating temperatures, and using $\mathrm{KNO}_{3}$ showed significant increases in germination speed and total germination. An alternating temperature of $25^{\circ} \mathrm{C}$ for $16 \mathrm{~h}$ (darkness) and $35^{\circ} \mathrm{C}$ for $8 \mathrm{~h}$ (d) stimulated germination and improved germination rate of seashore paspalum seeds in both water and $\mathrm{KNO}_{3}$ media. Marousky and West (1988) reported
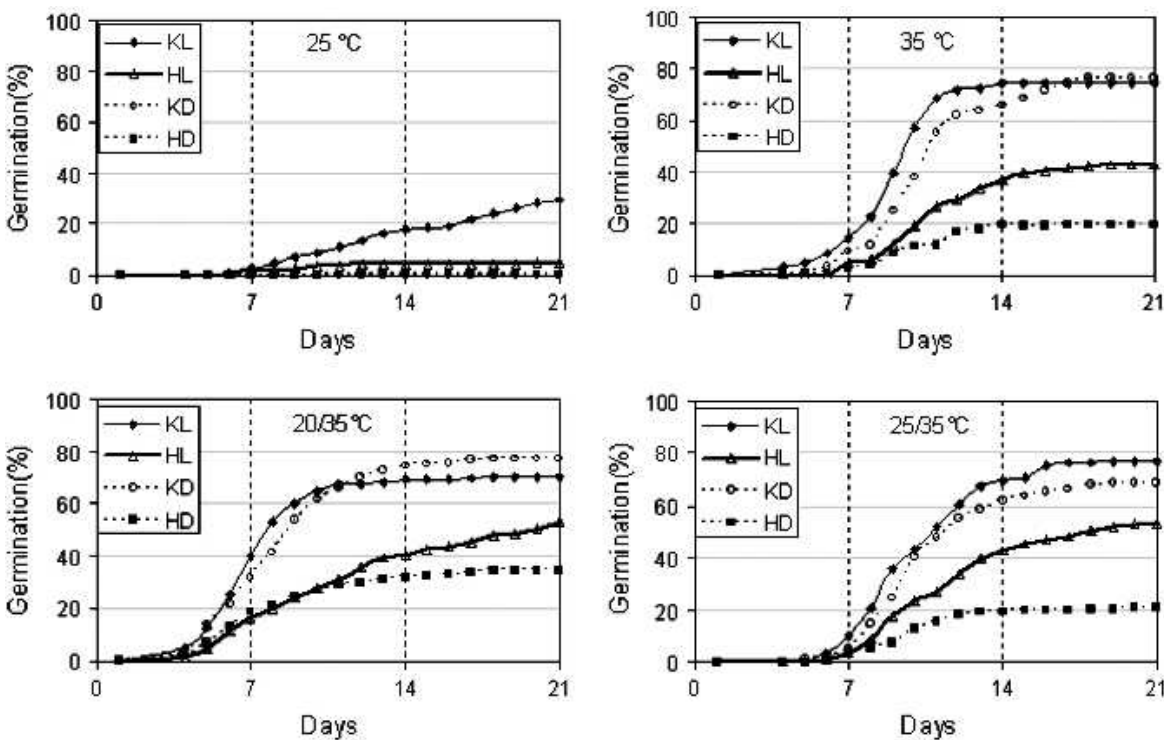

Fig. 1. The effect of environmental factors (light, temperature, and $\mathrm{KNO}_{3}$ ) on seed germination responses in seeded seashore paspalum. $\mathrm{KL}, 0.2 \% \mathrm{KNO}_{3}$ with light; $\mathrm{HL}, \mathrm{H}_{2} \mathrm{O}$ with light; $\mathrm{KD}, 0.2 \% \mathrm{KNO}_{3}$ without light; $\mathrm{HD}, \mathrm{H}_{2} \mathrm{O}$ without light.

that paspalum species require light and alternating temperatures for maximum germination. Our results also indicated that warmer altering temperatures were necessary for better germination rate. In water, light treatment increased germination at all temperatures. Above $30{ }^{\circ} \mathrm{C}$ is the optimum daytime temperature for germination. $\mathrm{KNO}_{3}$ in conjunction with light showed additive effect at 20 and $25^{\circ} \mathrm{C}$ constant. Germination at $20 / 35$ and $25 / 35^{\circ} \mathrm{C}$ in $0.2 \% \mathrm{KNO}_{3}$ media might be the best condition for germination testing. However, when we consider field application, germination at $25 / 35{ }^{\circ} \mathrm{C}$ with $0.2 \% \mathrm{KNO}_{3}$ treatment is more realistic condition.

Recommended test condition for seed germination is $25 / 35{ }^{\circ} \mathrm{C}$ with $0.2 \% \mathrm{KNO}_{3}$. However, most seeded grass varieties for golf courses and sports fields need fast germination speed and uniform germination rate. Our results indicated that only $10.3 \%$ of seeds were germinated within 1 week at recommended optimum condition. Therefore, further research is needed to improve speed and uniformity of germination for the fast establishment of grass field.

\section{Literature Cited}

Carpenter, J.A. 1958. Production and use of seed in seashore paspalum. J. Inst. Agr. Sci. 24:252256.

Carrow, R.N. and R.R. Duncan. 1998. Salt-affected turfgrass sites: assessment and management. Ann Arbor Press, Chelsea, Mich.

Colman, R.L. and G.P.M. Wilson. 1960. The effects of floods on pasture plants. Agr. Gaz. NSW 71:337-347.

Duncan, R.R. 1994. Seashore paspalum may be the grass for the year 2000. Southern Turf Manage. 5:31-32.

Duncan, R.R. and R.N. Carrow. 1999. Seashore Paspalum: The Environmental Turfgrass. Wiley, Hoboken, N.J.

Huang, B., R.R. Duncan, and R.N. Carrow. 1997. Drought-resistance mechanisms of seven warm-season grasses under surface soil drying: I. Shoot response. Crop Sci. 37:1858-1863.

Jiang, Y., R.R. Duncan, and R.N. Carrow. 2004. Assessment of low light tolerance of seashore paspalum and bermudagrass. Crop Sci. 44: 587-594.

Knoop, W.E. 1997. The Landscape Management Handbook. GCSAA and Advanstar Commun. Inc., Duluth, Minn.

Marousky, F.J. and S.H. West. 1988. Germination of bahiagrass in response to temperature and scarification. J. Amer. Soc. Hort. Sci. 113:845-849. 